\title{
Systematic review and meta-analysis on efficacy of traditional Chinese medicine for atrial fibrillation through cluster analysis
}

\author{
Yanrong Lei ${ }^{1 \#}$, Ying Tang ${ }^{2,3 \#}$, Ling Huang ${ }^{3,4}$, Ping $\mathrm{He}^{2,3}$ \\ ${ }^{1}$ Outpatient Department, Hospital of Chengdu University of Traditional Chinese Medicine, Chengdu, China; ${ }^{2}$ Operational Department, Sichuan \\ Provincial People's Hospital, University of Electronic Science and Technology of China, Chengdu, China; ${ }^{3}$ Chinese Academy of Sciences Sichuan \\ Translational Medicine Research Hospital, Chengdu, China; ${ }^{4}$ Education and Training Department, Sichuan Provincial People's Hospital, University \\ of Electronic Science and Technology of China, Chengdu, China \\ Contributions: (I) Conception and design: Y Lei, P He; (II) Administrative support: Y Tang; (III) Provision of study materials or patients: Y Lei, Y \\ Tang, P He; (IV) Collection and assembly of data: All authors; (V) Data analysis and interpretation: P He, L Huang; (VI) Manuscript writing: All \\ authors; (VII) Final approval of manuscript: All authors. \\ "These authors contributed equally to this work. \\ Correspondence to: Ping He; Ling Huang. Sichuan People's Hospital of Sichuan Academy of Medical Sciences, No. 18 Huanhua North Road, \\ Qingyang District, Chengdu, China. Email: HP_FSB@126.com; hhuangling521@163.com.
}

\begin{abstract}
Background: Traditional Chinese medicine (TCM) has shown excellent therapeutic effects in the treatment of heart diseases. This meta-analysis was to evaluate the therapeutic effects of TCM on patients with atrial fibrillation (AF).

Methods: Four databases were searched from their establishment to 1 April 2021 for randomized controlled trials (RCTs) on the treatment of AF using TCM. The Cochrane Handbook 5.0.2 was used to perform to bias risk assessment, and RevMan 5.3 was used for meta-analysis.

Results: A total of 7 references were included. It was found that compared with conventional Western medicine, the effective rate of TCM or the combined therapy of TCM and Western medicine was higher [mean difference $(M D)=1.85 ; 95 \%$ confidence interval $(\mathrm{CI}): 1.28$ to $2.68 ; \mathrm{Z}=3.26 ; \mathrm{P}=0.001$ ]; the success rate of conversion was increased $(\mathrm{MD}=1.58 ; 95 \% \mathrm{CI}: 1.02$ to $2.44 ; \mathrm{Z}=2.06 ; \mathrm{P}=0.04)$, the conversion time was shortened ( $\mathrm{MD}=-224.82 ; 95 \% \mathrm{CI}$ : -262.56 to $-187.08 ; \mathrm{Z}=11.68 ; \mathrm{P}<0.00001)$, the incidence of adverse reactions was reduced $(\mathrm{MD}=0.62 ; 95 \% \mathrm{CI}: 0.40$ to $0.97 ; \mathrm{Z}=2.11 ; \mathrm{P}=0.03$ ).

Discussion: The use of TCM to treat AF can improve clinical treatment efficiency, increase the success rate of conversion, and shorten the conversion time. Compared with conventional Western medicine, the combined therapy demonstrated better therapeutic effects.
\end{abstract}

Keywords: Clustering analysis; traditional Chinese medicine (TCM); atrial fibrillation (AF); meta-analysis; efficacy

Submitted Jun 11, 2021. Accepted for publication Aug 02, 2021.

doi: 10.21037/apm-21-1785

View this article at: https://dx.doi.org/10.21037/apm-21-1785

\section{Introduction}

Atrial fibrillation (AF) is a common arrhythmia in clinical practice. The China Society of Pacing and Electrophysiology (CSPE) believes that AF is the most serious disorder of atrial electrical activity arising from rapid and disordered AF waves (1). It mostly occurs in elderly patients. Studies have shown that its prevalence is approximately $0.5 \%$ in those aged $50-59$ years in China, and it is as high as $7.5 \%$ in those over 80 years old (2). Clinically, according to duration, AF can be divided into 5 categories: first-diagnosed AF (first diagnosis), paroxysmal $\mathrm{AF}$ (duration $\leq 7 \mathrm{~d}$, self-terminating), persistent $\mathrm{AF}$ (duration $>7 \mathrm{~d}$, recurrent attacks), long-term persistent AF (duration 
$\geq 1$ year, the patient has a desire for conversion), and permanent $\mathrm{AF}$ (duration $>1$ year, it cannot be terminated or relapses after termination, and the patient has no desire for conversion) (3). The etiology and pathogenesis of $\mathrm{AF}$ are complex. It may be caused by certain transient factors, acute diseases, cardiovascular diseases, and respiratory diseases. Patients with AF have an increased incidence of ischemic stroke, heart failure, and tachycardia cardiomyopathies (4,5), so timely treatment is essential.

The treatment of AF includes drug therapy and non-drug therapy. Non-drug therapy includes catheter radiofrequency ablation and electrical cardioversion therapy; however, they are expensive, and the recurrence rate is high. Therefore, drug therapy is still the main clinical approach (6). Although drug therapy helps to control ventricular rate, convert AF, and maintain sinus rhythm, it leads to many side effects, and patients easily develop drug resistance $(7,8)$.

With the continuous advancement of medical technology, traditional Chinese medicine (TCM) is playing an increasingly important role in the treatment of AF. In TCM, AF is classified in the category of "palpitations". Its etiology and pathogenesis can be summarized as root deficiency, lack of heart-qi, yin deficiency, stagnation of qi, blood stasis, and so on. Therefore, TCM treatment is aimed at restoring the pulse to relieve palpitations, promoting blood circulation to remove blood stasis, and nourishing Qi and Yin (9). Clinically, TCM treatment methods include radiotherapy and chemical treatment self-made prescription treatment, single Chinese medicine treatment, Chinese patent medicine treatment, and combined Chinese and Western medicine treatment (10). Many randomized controlled trials (RCTs) have analyzed the efficacy of TCM treatment on $\mathrm{AF}$, but a systematic review on the treatment of AF has not yet been performed. Herein, a meta-analysis was conducted on RCTs using TCM to treat AF, aiming to systematically evaluate the efficacy of TCM on AF. We present the following article in accordance with the PRISMA reporting checklist (available at https://dx.doi. org/10.21037/apm-21-1785).

\section{Methods}

\section{Literature inclusion and exclusion criteria}

Literature was selected as per the following inclusion criteria: (I) AF patients aged $\geq 18$ years old, with no limitations regarding gender; (II) RCTs published in English; (III) the experimental group received combined treatment, the control group received Western medicine treatment, and the baseline data of the 2 groups was comparable; and (IV) evaluation of efficacy referred to the Guiding Principles for Clinical Research of New Chinese Medicines (11). Exclusion criteria: (I) non-RCT studies; (II) participants were non-AF patients; (III) treatment methods were not the combined treatment and Western medicine treatment; (IV) unpublished literature or non-English literature; and $(\mathrm{V})$ literature with incomplete data.

\section{Literature retrieval}

The databases of PubMed, Embase, Medline, and Springer were searched from their establishment to 1 April 2021 for publicly published studies using TCM or combined therapy to treat AF, with "Atrial fibrillation", "Chinese Medicine", "traditional Chinese medicine", "randomized controlled trial", and "AF" search terms, which were linked using "and" or "or".

\section{Literature screening}

The bibliography was first imported into NoteExpress 3.2 (Aegean Software Company, Beijing, China) to identify duplicates, which were then excluded. Subsequently, irrelevant references were excluded via reading of titles and abstracts. Finally, inclusion of the reference was determined by full text screening according to the inclusion and exclusion criteria. Any inconsistency between the 2 researchers was resolved by discussion or arbitration by a third researcher.

\section{Data extraction}

The following data was collated: (I) basic information of the literature (document title, publication year, source, first author, author information); (II) general information of participants (gender, age, sample size, course of disease, number of cases dropping out or lost to follow-up); (III) study plans, intervention measures; and (IV) test indicators and outcome data. Then, 2 researchers conducted crosschecking. Any inconsistency was solved by discussion or arbitration by a third researcher.

\section{Literature quality assessment}

The bias risk of the included literature was assessed by Cochrane Handbook 5.0.2 (The Cochrane Collaboration, 


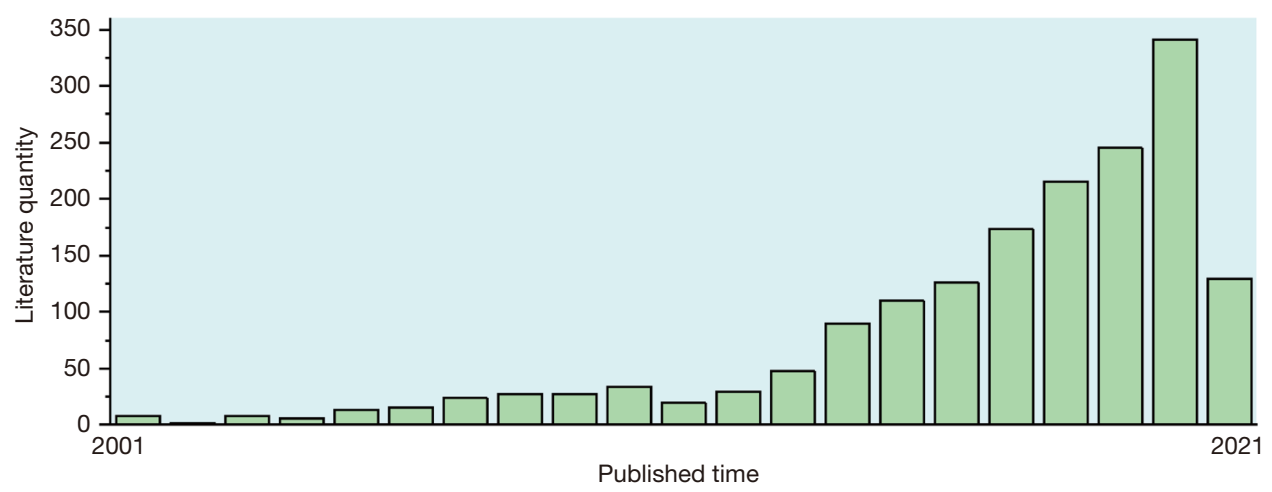

Figure 1 Clustering results.

2008), which factored in selection bias, implementation bias, measurement bias, follow-up bias, and other biases.

\section{Statistics}

The Cochrane Handbook 5.0.2 was used to assess the literature bias risk, and Review Manager 5.3 was used for meta-analysis. In meta-analysis, if $\mathrm{I}^{2} \geq 50$ and $\mathrm{P}<0.05$, the fixed effects model (FEM) was used; and if the $\mathrm{I}^{2}<50$, $\mathrm{P}>0.05$, the random effects models (REM) was used. For binary variables, relative risk (RR) was used as the effect size, and the $95 \%$ confidence interval $(95 \% \mathrm{CI}$ ) was calculated. $\mathrm{P}<0.05$ as the threshold for significance.

\section{Results}

\section{Clustering results}

The abovementioned 4 databases were searched, with "Atrial fibrillation" and "Chinese Medicine" as search terms, as shown in Figure 1.

\section{Literature retrieval}

We searched 4 English databases from their establishment to 1 April 2021 for RCTs using TCM or combined therapy to treat AF. Initially, 1,266 articles were identified. Then, 144 duplicates were excluded. After reading the title and the abstract, 926 references that were obviously irrelevant to the study were also excluded. Finally, a total of 7 references were included in this study after careful full-text reading. All included RCTs had been publicly published from 2004 to 2018 , involving 1,118 participants, with 618 cases in the experimental group and 500 cases in the control group. The baseline data of the 2 groups were comparable (Figure 2 and Table 1).

\section{Bias risk assessment of included literature}

(I) Generation of the random sequence: they were all RCTs, indicating a low risk (12-18). (II) Allocation concealment: 2 references $(16,17)$ used the double-blind method, indicating a low risk, and the remaining $5(12-15,18)$ did not mention it, indicating an unclear risk. (III) The blind method for participants: 1 reference (18) clearly mentioned "signing an informed consent form for the patient", indicating a high risk, and $2(16,17)$ mentioned that the participants were blinded, indicting a low risk. The remaining 4 (12-15) did not mention it, indicating an unclear risk. (IV) The blind method for the outcome assessor: 2 references $(16,17)$ used the blind method for the outcome assessors, suggesting low risk, and the remaining $5(12-15,18)$ did not mention it, suggesting an unclear risk. (V) Data integrity: the outcome data of all 7 references (12-18) was complete, suggesting a low risk. (VI) Selective reporting: all 7 references (12-18) were not selective reports, indicating a low risk. (VII) Other biases: it could not be determined whether there was other bias in all 7 references (12-18), suggesting an unclear risk (Figures 3 and 4).

\section{Effective rate of the treatment}

Of the 7 included documents, $5(12,13,15-17)$ reported the clinical efficacy of TCM on AF patients, involving a total of 1,050 case, including 586 cases in the experimental group, among whom 525 cases showed marked effects, and 464 cases in the control group, among whom 375 cases showed marked effects. After statistics, it was found that the 


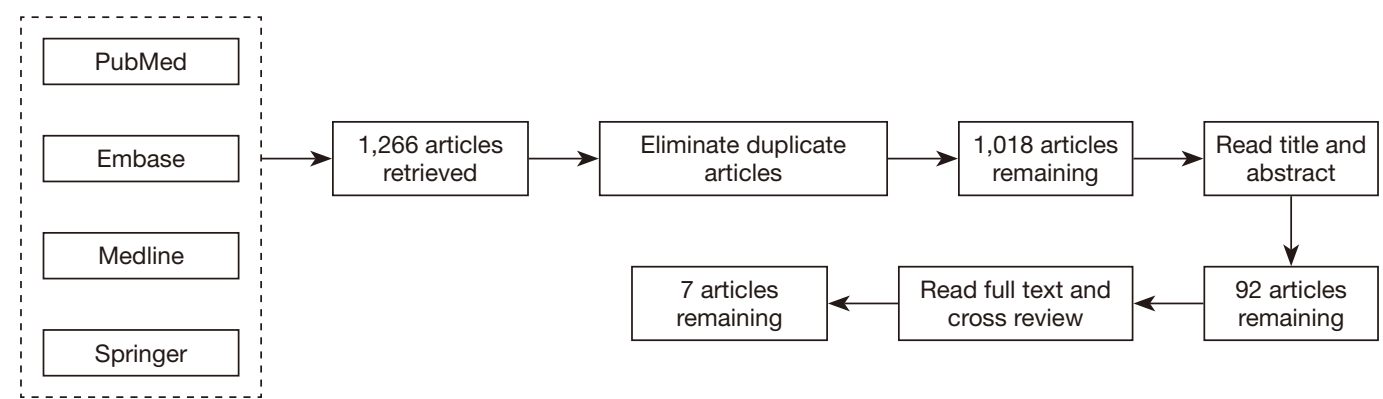

Figure 2 Literature retrieval process.

Table 1 Basic information of the included literature

\begin{tabular}{|c|c|c|c|c|}
\hline First author & Year of publication & Group & Sample size & Treatment approach \\
\hline Lian YZ (12) & & Control & 26 & warfarin sodium tablet \\
\hline \multirow[t]{2}{*}{ Wang M (13) } & 2006 & Experimental & 109 & Wenxin granule + amiodarone \\
\hline & & Control & 107 & Amiodarone \\
\hline Xie PY (14) & & Control & 15 & Amiodarone+ irbesartan \\
\hline \multirow[t]{2}{*}{ Deng M (15) } & 2010 & Experimental & 223 & Shenmai injection + amiodarone \\
\hline & & Control & 128 & Amiodarone \\
\hline Wang AH (16) & 2011 & Experimental & 106 & Shensongyangxin capsules + propafenone \\
\hline Liu Y (17) & & Control & 104 & Placebo \\
\hline \multirow[t]{2}{*}{ Zhang N (18) } & 2018 & Experimental & 20 & Wenxin granule + amiodarone \\
\hline & & Control & 21 & Amiodarone \\
\hline
\end{tabular}

homogeneity was good $\left(\mathrm{I}^{2}=0 \%, \mathrm{P}=0.46\right)$, so the $\mathrm{FEM}$ was used. The combined effect size was ( $M D=1.85 ; 95 \%$ CI: 1.28 to $2.68 ; \mathrm{Z}=3.26 ; \mathrm{P}=0.001$ ), suggesting that compared with Western medicine, the use of TCM raised the effective rate (Figure 5).

\section{Success rate of conversion}

Of the 7 included documents, $3(14,15,18)$ reported the conversion effects, involving a total of 419 participants, including 255 cases in the experimental group, among whom 193 were successfully converted, and 164 cases in the control group, among whom 107 were successfully converted. The heterogeneity was low $\left(\mathrm{I}^{2}=27 \%, \mathrm{P}=0.25\right)$, so the FEM was used. The combined effect size was (MD $=1.58 ; 95 \%$ CI: 1.02 to $2.44 ; Z=2.06 ; P=0.04$ ), suggesting that compared with Western medicine, TCM raised the conversion rate (Figure 6).

\section{Conversion time}

Of the 7 included documents, $3(14,15,18)$ reported the conversion time. The heterogeneity was low $\left(\mathrm{I}^{2}=40 \%\right.$, $\mathrm{P}=0.19)$, so the FEM was used. The combined effect size was $(M D=-224.82 ; 95 \%$ CI: -262.56 to $-187.08 ; Z=11.68$; $\mathrm{P}<0.00001)$, suggesting that compared with Western medicine treatment, TCM shortened the conversion time (Figure 7). 


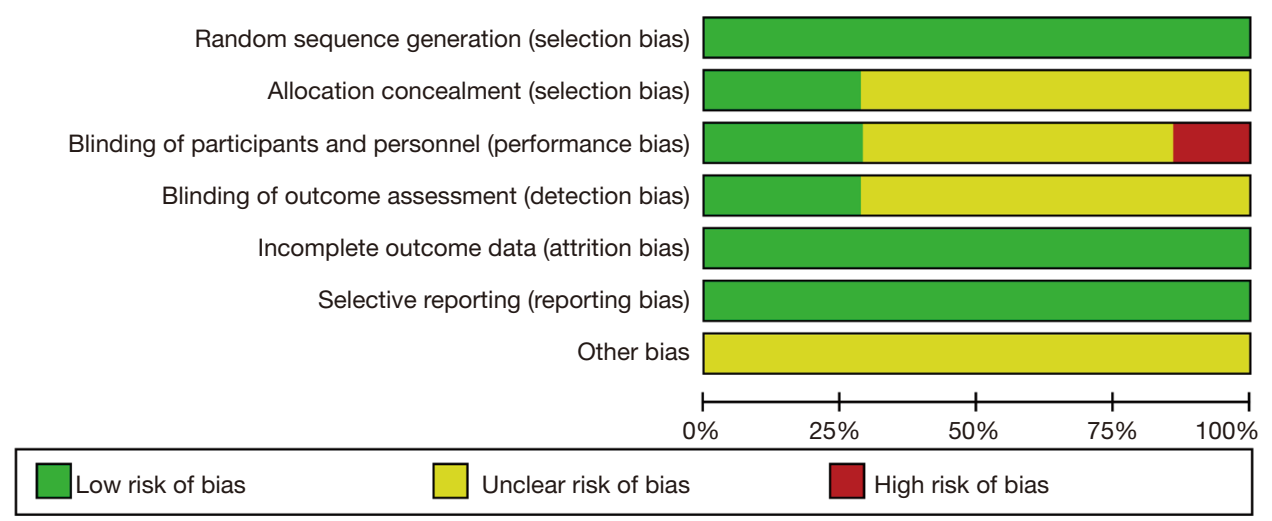

Figure 3 Bar chart showing the bias risk.

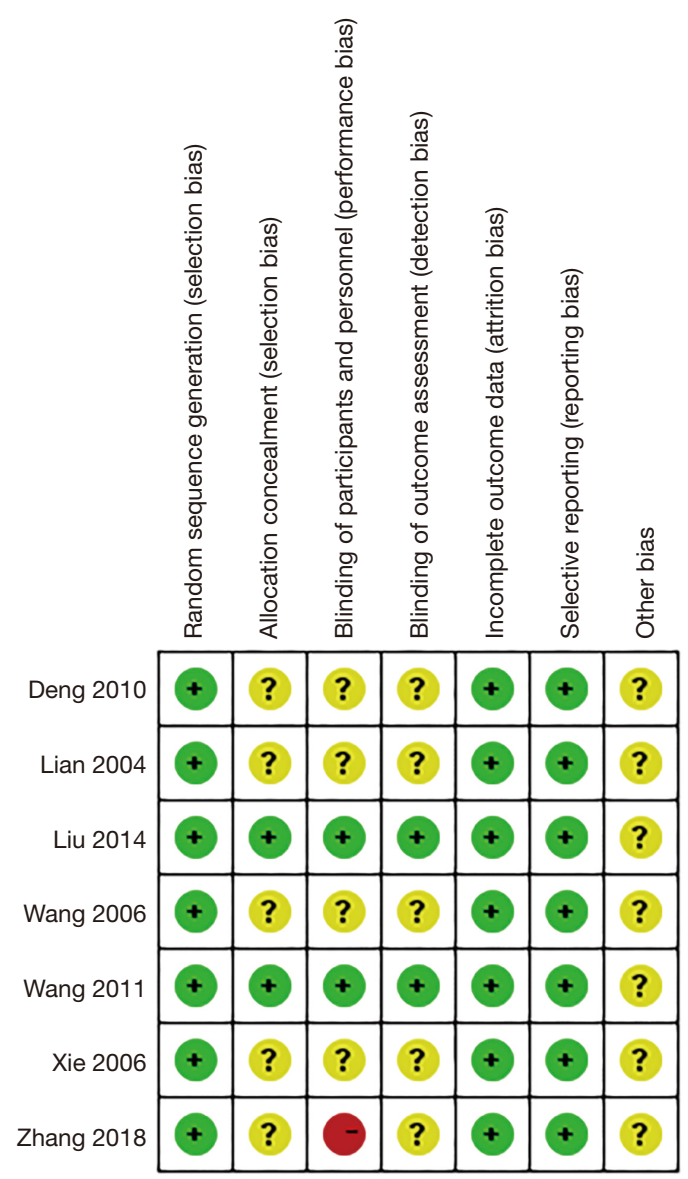

Figure 4 Diagram showing the bias risk.

\section{Incidence of adverse reactions}

Of the 7 included documents, 5 (12-16) reported the incidence of adverse reactions. The heterogeneity was low $\left(\mathrm{I}^{2}=27 \%, \mathrm{P}=0.24\right)$, so the FEM was used. The combined effect size was $(\mathrm{MD}=0.62 ; 95 \% \mathrm{CI}$ : 0.40 to $0.97 ; \mathrm{Z}=2.11$; $\mathrm{P}=0.03$ ), suggesting that compared with the conventional Western medicine, TCM reduced the incidence of adverse reactions (Figure 8).

\section{Publication bias}

The postoperative adverse reactions were basically distributed within the credible interval, indicating low bias. The points representing the effective rate of the treatment, success rate of conversion, conversion time, and incidence of adverse reactions were scattered in the credible interval, but both sides of the funnel chart were asymmetrical, indicating a certain publication bias (Figure 9).

\section{Discussion}

The incidence of AF, a common arrhythmia, gradually increases with age. If timely de-fibrillation is not realized, it is easy to develop left atrial thrombosis and arterial embolism, and those affected will experience hemodynamic abnormalities and atrial electrophysiological remodeling. Hence, prompt de-fibrillation is critical $(19,20)$. Although 


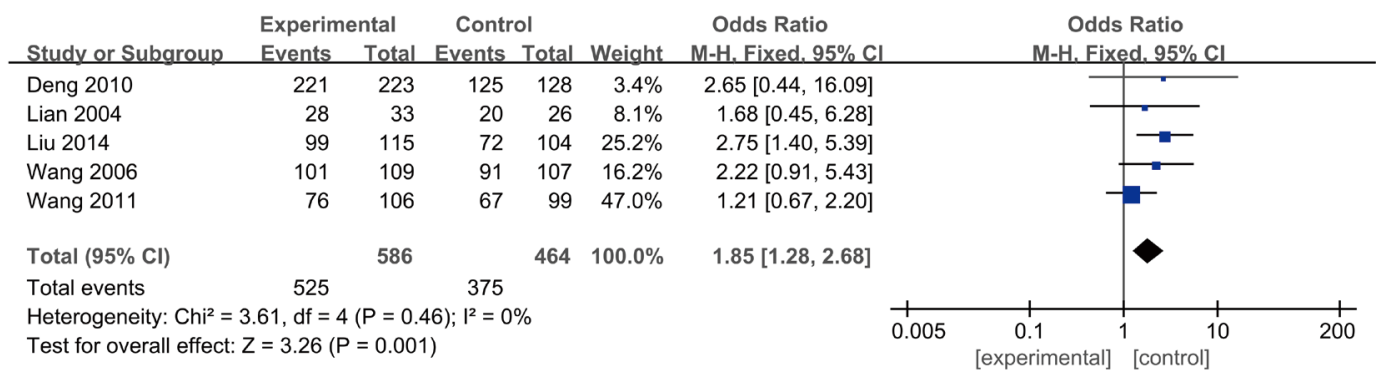

Figure 5 The effective rate.

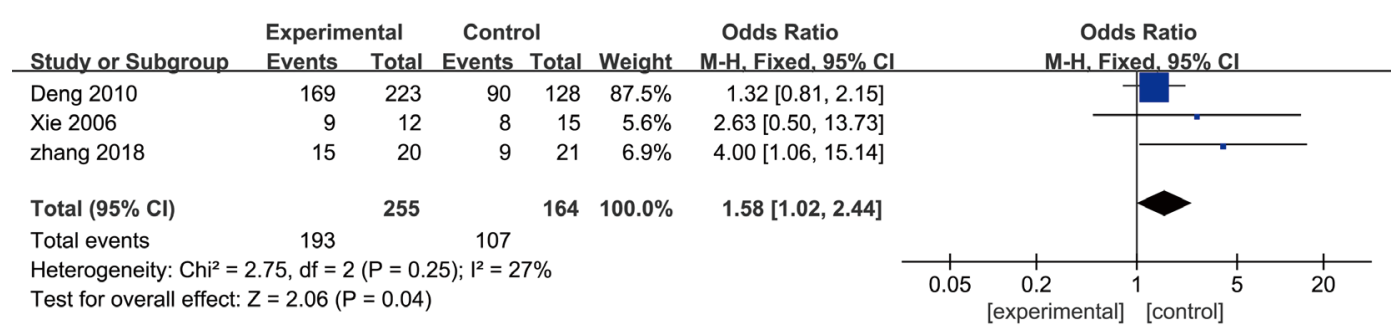

Figure 6 The success rate of conversion.

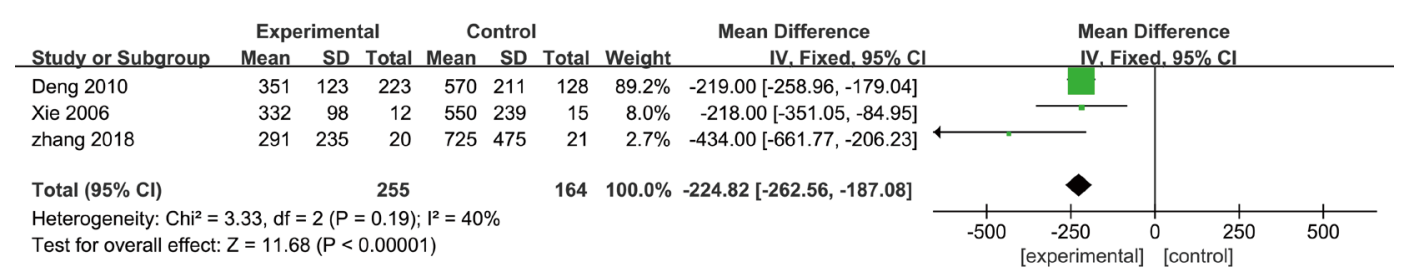

Figure 7 The conversion time.

\begin{tabular}{|c|c|c|c|c|c|c|c|c|c|c|}
\hline Study or Subgroup & $\begin{array}{l}\text { Experim } \\
\text { Events }\end{array}$ & $\begin{array}{l}\text { ntal } \\
\text { Total }\end{array}$ & $\begin{array}{l}\text { Contr } \\
\text { Events }\end{array}$ & Total & Weight & $\begin{array}{l}\text { Odds Ratio } \\
\text { M-H. Fixed. } 95 \% \mathrm{Cl}\end{array}$ & & $\begin{array}{r}\text { Odds } \\
\text { M-H. Fixe }\end{array}$ & $\begin{array}{l}\text { Ratio } \\
\text { d. } 95 \% \mathrm{Cl}\end{array}$ & \\
\hline Deng 2010 & 12 & 223 & 14 & 128 & $34.2 \%$ & $0.46[0.21,1.03]$ & & & & \\
\hline Lian 2004 & 2 & 33 & 2 & 26 & $4.3 \%$ & $0.77[0.10,5.90]$ & & & & \\
\hline Wang 2006 & 12 & 109 & 24 & 107 & $43.8 \%$ & $0.43[0.20,0.91]$ & & & & \\
\hline Wang 2011 & 9 & 106 & 8 & 99 & $15.4 \%$ & $1.06[0.39,2.85]$ & & & & \\
\hline Xie 2006 & 4 & 12 & 2 & 15 & $2.4 \%$ & $3.25[0.48,22.00]$ & & & & \\
\hline Total $(95 \% \mathrm{Cl})$ & & 483 & & 375 & $100.0 \%$ & $0.62[0.40,0.97]$ & & & & \\
\hline Total events & 39 & & 50 & & & & & & & \\
\hline \multicolumn{7}{|c|}{$\begin{array}{l}\text { Heterogeneity: } \text { Chi }^{2}=5.47, d f=4(P=0.24) ; I^{2}=27 \% \\
\text { Test for overall effect: } Z=2.11(P=0.03)\end{array}$} & $\begin{array}{l}+ \\
0.002\end{array}$ & 0.1 & $\begin{array}{c}10 \\
\text { [control] }\end{array}$ & 500 \\
\hline
\end{tabular}

Figure 8 The adverse reactions.

catheter ablation therapy has achieved good results, it is difficult to operate, and the long-term prognosis is not ideal (21). There is no "Atrial Fibrillation" recorded in the classics of TCM, but it can be classified under the "palpitations" category based on its clinical symptoms. In
TCM, AF is caused by blood stasis, so the treatment should promote blood circulation and remove blood stasis (22).

To systematically evaluate the efficacy of TCM on AF patients, a meta-analysis was conducted on 7 references, including 1,118 participants. It was found that TCM or 

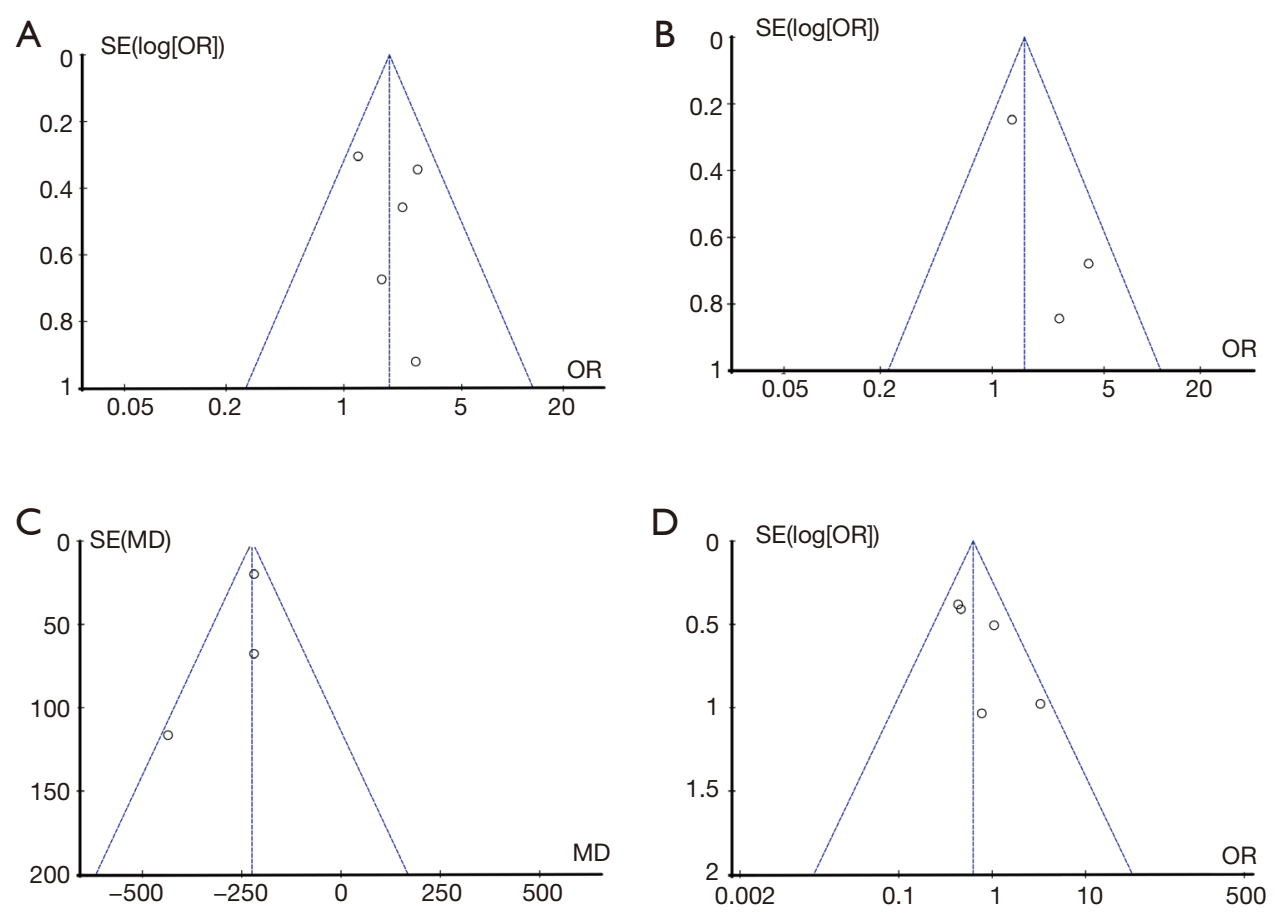

Figure 9 Funnel chart showing the evaluation results of each indicator. (A) Effective rate of the treatment; (B) success rate of conversion; (C) conversion time; (D) incidence of adverse reactions.

the combined therapy can improve the clinical treatment effects, lift the success rate of conversion, and shorten the conversion time, and that TCM treatment of AF leads to fewer adverse reactions, which was similar to the research results of He et al. [2018] (23). When using TCM to treat patients with $\mathrm{AF}$, although there are various clinical symptoms, the treatment methods are nothing more than replenishing Qi and nourishing Yin, promoting blood circulation, and resolving blood stasis, which has been shown to achieve good therapeutic effects.

\section{Conclusions}

This meta-analysis systematically evaluated the efficacy of TCM on AF patients. The results showed that the treatment of AF by TCM can raise the effective rate, increase the success rate of conversion, shorten conversion time, and reduce the incidence of adverse reactions. However, some limitations should be noted. The number of included studies was small, which truncated the power of the study. In the future studies, more high-quality and multi-centered RCTs should be incorporated to strengthen the findings of the study.

\section{Acknowledgments}

Funding: None.

\section{Footnote}

Reporting Checklist: The authors have completed the PRISMA reporting checklist. Available at https://dx.doi. org/10.21037/apm-21-1785

Conflicts of Interest: All authors have completed the ICMJE uniform disclosure form (available at https://dx.doi. org/10.21037/apm-21-1785). The authors have no conflicts of interest to declare.

Ethical Statement: The authors are accountable for all aspects of the work in ensuring that questions related to the accuracy or integrity of any part of the work are appropriately investigated and resolved.

Open Access Statement: This is an Open Access article distributed in accordance with the Creative Commons Attribution-NonCommercial-NoDerivs 4.0 International License (CC BY-NC-ND 4.0), which permits the non- 
commercial replication and distribution of the article with the strict proviso that no changes or edits are made and the original work is properly cited (including links to both the formal publication through the relevant DOI and the license). See: https://creativecommons.org/licenses/by-nc-nd/4.0/.

\section{References}

1. Lau DH, Linz D, Sanders P. New Findings in Atrial Fibrillation Mechanisms. Card Electrophysiol Clin 2019;11:563-71.

2. Wang Z, Chen Z, Wang X, et al. The Disease Burden of Atrial Fibrillation in China from a National Crosssectional Survey. Am J Cardiol 2018;122:793-8.

3. Margulescu AD, Mont L. Persistent atrial fibrillation vs paroxysmal atrial fibrillation: differences in management. Expert Rev Cardiovasc Ther 2017;15:601-18.

4. Ciconte G, Conti M, Evangelista M, et al. Atrial Fibrillation in Autoimmune Rheumatic Diseases: from Pathogenesis to Treatment. Rev Recent Clin Trials 2018;13:170-5.

5. Packer M. Characterization, Pathogenesis, and Clinical Implications of Inflammation-Related Atrial Myopathy as an Important Cause of Atrial Fibrillation. J Am Heart Assoc 2020;9:e015343.

6. Westerman S, Wenger N. Gender Differences in Atrial Fibrillation: A Review of Epidemiology, Management, and Outcomes. Curr Cardiol Rev 2019;15:136-44.

7. Steinberg JS, Shabanov V, Ponomarev D, et al. Effect of Renal Denervation and Catheter Ablation vs Catheter Ablation Alone on Atrial Fibrillation Recurrence Among Patients With Paroxysmal Atrial Fibrillation and Hypertension: The ERADICATE-AF Randomized Clinical Trial. JAMA 2020;323:248-55.

8. Blomström-Lundqvist C, Gizurarson S, Schwieler J, et al. Effect of Catheter Ablation vs Antiarrhythmic Medication on Quality of Life in Patients With Atrial Fibrillation: The CAPTAF Randomized Clinical Trial. JAMA 2019;321:1059-68.

9. Dong Y, Liao J, Yao K, et al. Application of Traditional Chinese Medicine in Treatment of Atrial Fibrillation. Evid Based Complement Alternat Med 2017;2017:1381732.

10. Qiu R, Hu J, Huang Y, et al. Outcome reporting from clinical trials of non-valvular atrial fibrillation treated with traditional Chinese medicine or Western medicine: a systematic review. BMJ Open 2019;9:e028803.

11. Brilakis ES, Mashayekhi K, Tsuchikane E, et al. Guiding
Principles for Chronic Total Occlusion Percutaneous Coronary Intervention. Circulation 2019;140:420-33.

12. Lian YZ, Li YG, Zhang HL, et al. Study on effect of compound salvia pellet in preventing atrial fibrillation with left atrial thrombosis. Chinese Journal of Integrative Medicine 2004;10:59-62.

13. Wang $M, Y u$ YB, Huang SE. Clinical observation on effect and safety of combined use of wenxin granule and amiodarone for conversion of auricular fibrillation. Zhongguo Zhong Xi Yi Jie He Za Zhi 2006;26:445-8.

14. Xie PY, Shen SH. Effect of combination of Chinese and Western medicines on sinus rhythm maintenance in patients with auricular fibrillation after conversion. Zhongguo Zhong Xi Yi Jie He Za Zhi 2006;26:644-6.

15. Deng M, Sui XQ, Zhu SB, et al. Clinical observation on the treatment of atrial fibrillation with amiodarone combined with Shenmai Injection. Chin J Integr Med 2010;16:453-6.

16. Wang AH, Pu JL, Qi XY, et al. Evaluation of shensongyangxin capsules in the treatment of paroxysmal atrial fibrillation: a randomized, double-blind and controlled multicenter trial. Zhonghua Yi Xue Za Zhi 2011;91:1677-81.

17. Liu Y, Li N, Jia Z, et al. Chinese medicine shensongyangxin is effective for patients with bradycardia: results of a randomized, double-blind, placebo-controlled multicenter trial. Evid Based Complement Alternat Med 2014;2014:605714.

18. Zhang N, Tse G, Dahal S, et al. Efficacy of Wenxin Keli Plus Amiodarone versus Amiodarone Monotherapy in Treating Recent-Onset Atrial Fibrillation. Cardiol Res Pract 2018;2018:6047271.

19. Tousoulis D. Biomarkers in Atrial Fibrillation; From Pathophysiology to Diagnosis and Treatment. Curr Med Chem 2019;26:762-4.

20. Nattel S, Dobrev D. Controversies About Atrial Fibrillation Mechanisms: Aiming for Order in Chaos and Whether it Matters. Circ Res 2017;120:1396-8.

21. Poole JE, Bahnson TD, Monahan KH, et al. Recurrence of Atrial Fibrillation After Catheter Ablation or Antiarrhythmic Drug Therapy in the CABANA Trial. J Am Coll Cardiol 2020;75:3105-18.

22. Sun LJ, Du X, Liu SW, et al. Current status of the clinical practice and analysis on the ratioanl prescription of antiarrhythmic drugs in Chinese patients with atrial fibrillation: Results from the Chinese Atrial Fibrillation Registry (CAFR) trial. Zhonghua Xin Xue Guan Bing Za 
Zhi 2020;48:740-7.

23. He Z, Zheng M, Xie P, et al. Wenxin Keli for atrial fibrillation: Protocol for a systematic review and meta- analysis. Medicine (Baltimore) 2018;97:e0390.

(English Language Editor: J. Jones)

Cite this article as: Lei Y, Tang Y, Huang L, He P. Systematic review and meta-analysis on efficacy of traditional Chinese medicine for atrial fibrillation through cluster analysis. Ann Palliat Med 2021;10(8):8982-8990. doi: 10.21037/apm-21-1785 